\title{
Triaminic Cold
}

National Cancer Institute

\section{Source}

National Cancer Institute. Triaminic Cold. NCI Thesaurus. Code C29514.

Any of the commercial combination preparations, by Novartis, containing the antihistamine chlorpheniramine maleate and the decongestant pseudoephedrine hydrochloride, either alone or in combination with the analgesic antipyretic acetaminophen and/or the antitussive dextromethorphan hydrobromide. Chlorpheniramine maleate, an antihistamine, blocks the effects of histamine, thereby preventing symptoms such as sneezing and itchy, watery eyes, runny nose and sore throat. Pseudoephedrine hydrochloride, a sympathomimetic agent, acts as a decongestant by inducing vasoconstriction mediated via alpha-adrenergic receptors. This reduces blood flow, decreases swelling and prevents nasal and sinus congestion. 